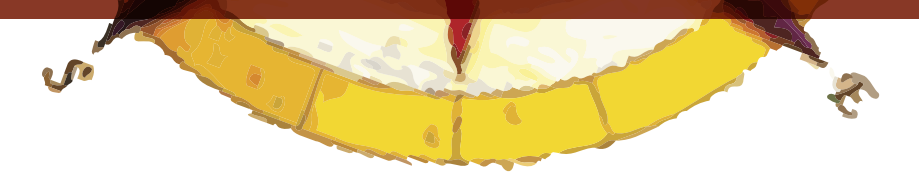

\title{
SOBRE O ENSINO DE GEOGRAFIA NA INTERFACE COM A ARTE
}

\author{
Dirce Maria Antunes Suertegaray
}

\section{RESUMEN}

En este artículo se trata de componer un diálogo a partir de la lectura de un texto de Friedrich Ratzel (1904) publicado en 2010, que expone su interpretación de la naturaleza en relación con el arte y la enseñanza de la geografía en el contexto actual. La perspectiva de abordar la enseñanza de la geografía del arte, ya propuesta en ese texto de Ratzel (1904), surge como una posibilidad en muchas de las experiencias de los profesores que se dedican a enseñar a los niños y jóvenes, y se constituye en una propuesta asociada a las políticas públicas de enseñanza de la geografía en Brasil. Para llevar a la práctica el tema de la Geografía y el Arte, fueron elegidas tres acciones docentes. La primera, se refiere al trabajo realizado por Kornalewski da Silva, con el Proyecto Amora do Colégio de Aplicação (CAP/UFRGS, 2008), como becario de iniciación científica / FAPERGS. La segunda, ha sido desarrollada por el profesor Rossato (2010) también con el Proyecto Amora (CAP / UFRGS). La tercera acción fue desarrollada por Pires da Silva (2008) durante la realización de su tesis doctoral en el Programa de Posgrado en Geografía (POSGEA / UFRGS, 2008), con estudiantes de escuela secundaria. Los proyectos aquí analizados, buscan reflejar y construir conceptos tales como naturaleza, medio ambiente y paisaje, así como también promover la construcción de conocimiento sobre espacio/planetas/satélites, sobre los movimientos de la Tierra, las estaciones, los tipos de nubes, las precipitaciones, entre otros. Asimismo permiten, a través de diferentes expresiones artísticas, trabajar contenidos que a veces son complejos para los estudiantes de primaria.

Palabras clave: naturaleza, medio ambiente, paisaje, arte.

\section{RESUMO}

Neste artigo o propósito é compor um diálogo a partir da leitura de Ratzel (1904) publicado em 2010 onde expõe sua interpretação da natureza em relação com a Arte e, o ensino da Geografia no contexto atual. A perspectiva de aproximação, no ensino de Geografia da Arte, já proposta, nesse texto de Ratzel (1904), emerge como possibilidade em muitas das experiências de professores que se dedicam a ensinar crianças e jovens e constitui proposta que se associa às políticas públicas de ensino de Geografia no Brasil. Para trazer a prática relativa ao tema Geografia e Arte foram escolhidas três ações docentes. A primeira diz respeito ao trabalho construído por Kornalewski da Silva junto ao Projeto Amora do Colégio de Aplicação (CAP/UFRGS, 2008) como bolsista de Iniciação Científica/FAPERGS. A segunda vem sendo desenvolvida pela professora Rossato (2010) também junto ao Projeto Amora (CAP/UFRGS). A terceira ação foi desenvolvida por Pires da Silva (2008) durante a construção de sua dissertação de mestrado no programa de Pós-graduação em Geografia 
(POSGEA/UFRGS, 2008), com alunos do ensino médio. Os projetos aqui trabalhados buscaram refletir e construir conceitos como os de natureza, ambiente e paisagem, como também promoveram a construção de conhecimento sobre espaço/planetas/satélites, movimentos da Terra, estações do ano, tipos de nuvens, precipitações, entre outros. Permitem, através de diferentes expressões artísticas, tratar de conteúdos, por vezes, complexos para o entendimento dos alunos do ensino fundamental.

Palavras Chaves: natureza, ambiente, paisagem, arte.

\begin{abstract}
In this article the aim is to compose a dialog from the reading of Ratzel (1904) published in 2010 which sets out its interpretation of nature in relation to art and the teaching of geography in the current context. The prospect of approaching the teaching of Geography of Art, as proposed in this text, Ratzel (1904) emerges as a possibility in many of the experiences of teachers who are dedicated to teaching children and youth and is proposed which combines the public policy teaching of geography in Brazil. To bring the practice on the topic Geography and Art were chosen three teaching actions. The first concerns the work constructed by Kornalewski da Silva Amora Project by the College Application (CAP /UFRGS, 2008) as scholarship of scientific initiation/FAPERGS. The second has been developed by Professor Rossato (2010) also with the Amora Project (CAP/UFRGS). The third action was developed by Pires da Silva (2008) during construction of his dissertation in the Graduate Program in Geography (POSGEA/UFRGS, 2008), with high school students. The projects worked here sought to reflect and buildconcepts such as nature, environment and landscape, but also promoted the construction of knowledge about space / planets / satellites, Earth movements, seasons, types of clouds, precipitation, among others. These allow, through different artistic expressions, dealing with content, sometimes complex, to the understanding of elementary school students.
\end{abstract}

Keywords: nature, environment, landscape, art.

Desde que a espada e a cruz desembarcaram em terras americanas, a conquista europeia castigou a adoração da natureza, que era pecado de idolatria, com sentenças de açoite, forca ou fogo. A comunhão entre a natureza e as pessoas, costume pagão, foi abolida em nome de Deus e, depois, em nome da civilização. Em toda a América, e no mundo, continuamos pagando as consequências desse divórcio obrigatório.

A natureza não é muda.

Eduardo Galeano, 2010.

A epígrafe retirada de um texto do escritor uruguaio Eduardo Galeano é reveladora da espoliação da natureza na América Latina, processo que ainda está em curso. Diante disso, considera-se relevante que a Geografia aprofunde a discussão e o conhecimento da natureza e suas transformações no ensino de Geografia, desde os anos iniciais da educação formal e mesmo no processo de educação informal. Para além da compreensão da natureza, o resgate de seu valor como condição de existência poderá ser sensibilizado através de uma educação que privilegie sua relação com a Arte.

Este artigo pretende com base no resgate de um clássico da Geografia, Ratzel 1904, compor um diálogo a partir da leitura desse autor, sobre a interpretação da natureza na relação com a Arte e as 
proposições no ensino da Geografia na atualidade. Para iniciar, cabe apresentar uma colocação de Ratzel no referido texto. Esta revela em certa medida, o que constitui o centro de suas preocupações naquele momento histórico:

A ciência não é suficiente para entender a linguagem da natureza. Para muitas pessoas, a poesia e a arte são intérpretes mais compreensíveis da natureza do que a ciência. E o professor que apela para o sentimento, pode aproximar seus alunos às grandezas da natureza proporcionando-lhes relacionamentos mais vibrantes, mais dinâmicos com elas. Sobre a interpretação da natureza [Über Naturschilderung]. (Ratzel, 1904, p. 157).

Este texto é revelador de algo que vem, cada vez mais, sendo colocado como fundamental no ensino de Geografia, em particular nos níveis fundamentais e médios. Não é de estranhar que, um texto com essa abordagem, privilegiando a estética na educação, escrito por Ratzel (1904), nos cause estranhamento. Busco, através desta citação, indicar o quanto as novas proposições, colocadas hoje para o ensino de Geografia, privilegiando a estética e a arte, como processo educativo nada tem de tão inovador na atualidade, embora, seja fundamental esse resgate, na contemporaneidade, pela sua importância na formação da pessoa.

Para um geógrafo, particularmente, aqueles que se dedicaram aos estudos da natureza, a expressão artística através do desenho sempre foi algo inerente ao seu aprendizado. A geografia brasileira tem em Aziz N. Ab'Saber, Carlos Augusto F. Monteiro, Ivo Lauro Müller Filho, entre outros, essa aproximação. Seus desenhos ilustraram suas aulas e, mais do que isso, reconstituíram paisagens, dinamizadas por processos por meio da elaboração de desenhos nos clássicos quadros negros e giz.

Recorrer o campo, observar e registrar, práticas clássicas da Geografia, sempre se associaram ao desenho, ao croqui, ao registro da paisagem, seja ela rural ou urbana. Desde os clássicos podemos ver a Arte associada à sistematização do conteúdo.

Ratzel (1904) afirma que a arte é capaz de aproximar o conhecimento, enquanto a ciência, por ser mais abstrata, distancia. Certamente que Ratzel se referia ao contexto da época e de como nesta época a ciência era construída, através de métodos que, partindo da observação, tendiam a padronizar a fim de poder generalizar. As generalizações, por sua vez, atingem tal grau de abstração que, muitas vezes, se tornam distantes dos educandos de outras pessoas.

Certamente é importante para a análise da ciência não se deter em um fenômeno, mas avançar na direção de compará-los com outros e testar as mais diversas verificações na procura dos seus aspectos comuns, classificá-los, subordinando-os em conceitos, formando abstrações. Mas aquela [análise científica] que esquecesse ou desprezasse a observação, colocando o pensamento abstrato acima de tudo, prestigiando conceitos desencarnados e palavras vazias mais do que as imagens das impressões imediatas, afastaria, em outras palavras, a arte da ciência, contestaria sua natureza e, consequentemente, seria apenas uma doença de ciência (Ratzel, 1904, p. 159)

Para além das artes, a natureza em Ratzel era representada em seu conjunto, como sendo a articulação de seus constituintes através da pintura de paisagens que devia representá-la o mais próximo da realidade. Ao se referir à paisagem, retomava os naturalistas desse tempo, como exemplo. Ratzel concebia que a representação através da pintura era mais concreta e, por isso, mais compreensível no processo educativo. Ao mesmo tempo revela na sua leitura que paisagem é representação e, sendo assim, ela apresenta nuances que dizem respeito à subjetividade do pintor ao escolher o que irá reproduzir, a partir de que ângulo de visão vai escolher matizes de luz e sombra. 
Existe um ponto máximo de imitação da natureza, no qual uma imagem aparece menos como um resultado artístico do que como uma criação da natureza, sem que com isso deixe de ser uma obra de arte. Mas não são os pardais que bicam nas uvas pintadas que fazem o juízo superior sobre o êxito da obra de arte. Seguramente só posso retratar um cristal de rocha ou uma concha do mar como a natureza os formou: nisso eu tenho que me subordinar à natureza sem mais, mas o seu desenho passa pelo meu espírito (Ratzel, 1904, p. 162).

O texto revela, na perspectiva da docência, a possibilidade de, para ensinar, unir razão e emoção. Esta é uma questão discutida contemporaneamente. A construção cultural moderna promoveu tal separação. O positivismo privilegiou a observação, como bem aponta Ratzel. A ciência, nessa época, se interessava em observar, comparar, classificar, através de conceitos, os fenômenos estudados. A racionalidade deste procedimento favoreceu que, na ciência, e por extensão no ensino, a emoção, a sensibilidade, numa dimensão mais específica, a Arte, ficasse relegada a um plano secundário, só sendo viável para aqueles cuja sensibilidade artística fosse uma característica própria.

A perspectiva de aproximação, no ensino de Geografia da Arte, já proposta, nesse texto de Ratzel (1904), emerge como possibilidade em muitas das experiências de professores que se dedicam a ensinar jovens e crianças na atualidade. Observa-se essa proposição desde as normativas que derivam das propostas políticas e de Estado, no caso do Brasil, para a educação, às experiências construídas em sala de aula por diferentes professores por meio de diferentes possibilidades: literatura, desenho, pintura, música. Neste artigo, a intenção é revelar algumas dessas proposições, no sentido de promover o diálogo com os professores envolvidos no ensino de Geografia.

A experiência de análise de livros didáticos nos anos de 2003, 2008, 2009, 2010, como participante do Plano Nacional do Livro Didático (PNLD) permite dizer que, inclusive, nos livros de Geografia mais atuais há uma introdução do conteúdo artístico. No entanto, este está condicionado, especialmente, quando se trata de artes plásticas, a apresentar quadros/telas de artistas sejam estes clássicos, reveladores das paisagens do passado, sejam estes modernistas.

Esses quadros/telas trazidos nos livros, por vezes, não atingem a sensibilidade dos jovens e crianças, e, ao mesmo tempo, não se observam processos educativos que favoreçam a reflexão e mesmo a possibilidade de construção artística, visto que não apresentam associação com o conteúdo mais específico trazido nos referidos livros.

Proposições como estas de articulação ciência e arte, entre outras associações, nos remete a pensar sobre a necessidade sempre emergente do trabalho interdisciplinar que, embora, teoricamente tenha sido muito debatido, nas ações empreendidas, esta proposição torna-se de difícil implantação.

Práticas interdisciplinares só são possíveis mediante o diálogo e o reconhecimento do trabalho do outro, o que se denomina de transdisciplinaridade como capacidade de trânsito ou mobilidade, de estar na fronteira para poder entender e dialogar com o diferente.

É sobre esta prática mais dialógica, esse colocar-se na fronteira que escolhi apresentar neste texto experiências de ensino de Geografia por meio da Arte, para, a partir delas, refletir sobre seus êxitos e suas possibilidades. 


\section{AS PRÁTICAS ESCOLHIDAS}

Para trazer à prática relativa ao tema Geografia e Arte escolhi três ações docentes. Uma delas diz respeito ao trabalho elaborado por Pâmela Kornalewski da Silva, acadêmica de Geografia que desenvolveu atividade de pesquisa e extensão, junto ao Projeto Amora do Colégio de Aplicação (CAP/UFRGS, 2008). Neste projeto, se revela a preocupação de resignificar, no contexto do ensino, em particular com crianças de $5^{\circ}$ ano, o conceito de ambiente. O segundo é desenvolvido pela professora Maíra S. Rossato (2010) também junto ao Projeto Amora (CAP/UFRGS). Esta atividade vincula Geografia e literatura. A autora, por meio de produção textual e de contação de história, demonstra como a literatura pode ensinar/aprender, desdobrando-se essa atividade em perspectivas interdisciplinares no cotidiano da escola. O terceiro foi desenvolvido por Pires da Silva (2008) durante a construção de sua dissertação de mestrado no programa de Pós-graduação em Geografia (POSGEA/UFRGS, 2008), com alunos do ensino médio. Este permitiu que o autor, ao reconhecer um fenômeno, e, entendê-lo, qual seja, os areais do Rio Grande do Sul nas suas dinâmicas, buscou resignificá-lo, por meio de uma atividade com jovens, alunos do ensino médio. Esta atividade teve como produto final a produção de desenhos de paisagens e/ou poesias, além da produção de fotos.

As três experiências buscam na produção de maquetes, na literatura infantil, no desenho e na poesia oferecerem aos alunos uma possibilidade de ensino que aproxime o conhecimento científico e o artístico.

\section{CROQUIS E MAQUETES NA CONSTRUÇÃO DO CONCEITO DE NATUREZA E AMBIENTE}

O conceito de ambiente tem sua origem na Biologia, e num grande número de casos ele é confundido, ou considerado equivalente ao de natureza. Para alguns geógrafos, não sendo este um conceito eminentemente geográfico, não caberia à Geografia discuti-lo, caberia aceitá-lo conforme a leitura produzida pela Biologia. Como já se referiu Milton Santos (1997), um conceito adotado por um campo de conhecimento sem ser resignificado, no campo de abordagem específica, torna-se uma metáfora. Então, cabe resignificar o conceito de ambiente seja no âmbito da Geografia como campo do conhecimento, seja no âmbito da educação.

A primeira atividade a ser relatada diz respeito ao projeto "Educação ambiental - Vivências no urbano, de responsabilidade de Kornalewski da Silva, 2008 sob minha orientação em sua atividade de pesquisa/ensino. Seu objetivo visou uma articulação entre Geografia e Educação Ambiental, direcionada ao ensino público em nível fundamental, na tentativa de buscar uma abertura ao debate teórico-metodológico da questão ambiental na sua relação com o ensino de Geografia. Mais especificamente, a autora se propunha, através de práticas de sensibilização, e/ou ações de busca de conscientização, promover o entendimento e a transformação do ambiente, no caso o ambiente urbano (bairro de moradia dos alunos envolvidos no projeto). A ação educativa tomou como ponto de partida a vivência em lugares determinados (bairro e escola).

As etapas desta atividade iniciaram com uma fase de divulgação, sensibilização e adesão de um grupo de alunos à atividade. Após a organização do grupo as atividades foram iniciadas por meio de uma oficina denominada "Construindo a maquete de meu bairro". Esta oficina ocorreu em diferentes momentos quando foram desenvolvidas a seguintes atividades: 
- Descrição do ambiente do bairro, saída de campo (campus do Vale/UFRGS) acompanhada de uma reflexão sobre: $\mathrm{O}$ que há no ambiente do colégio que eles gostariam que tivesse no ambiente do bairro e vice-versa?

- Fabricação de tintas naturais utilizando materiais do ambiente escolar (tomate, beterraba, terra, bulbo da beterraba, giz, pó de café, casca de uva, casca de ovos etc.)

- Discussão no grupo sobre o bairro que desejam para si e elaboração do projeto do bairro utilizando recortes e desenhos.

- Construção de maquetes com base no projeto elaborado inicialmente e pintado com as tintas produzidas com elementos do ambiente.

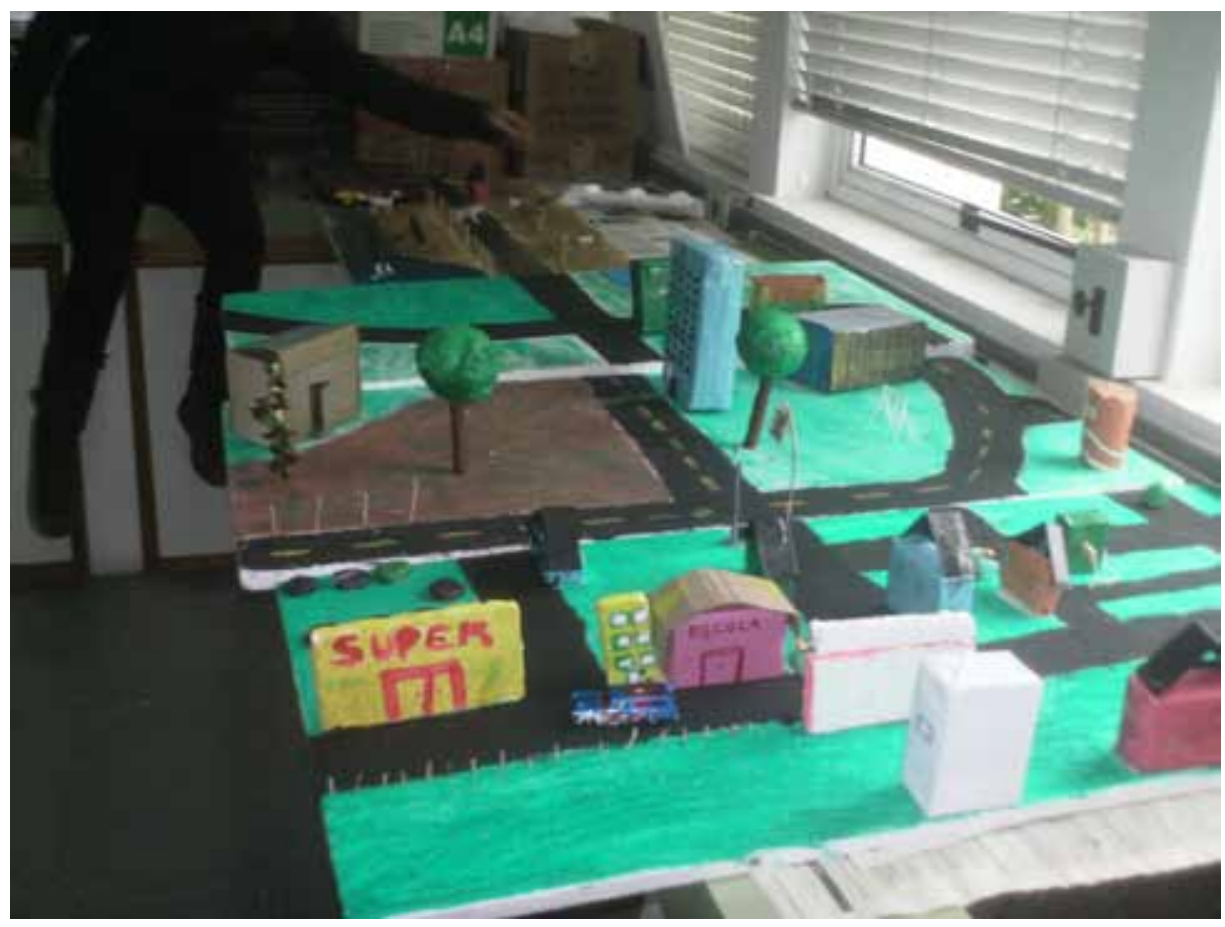

Figura 1. Exemplo de maquete produzida pelas crianças inscritas no projeto: Educação ambiental - Vivências no urbano. Extraído do relatório de Kornalewski da Silva. (PIBIC/FAPERGS, 2008) Inédito.

Análise e reflexões. Nesta fase, os alunos envolvidos nas atividades promoveram um debate e elaboraram reflexões sobre os elementos que o grupo considerou importantes na construção do bairro (Figura 2a), construindo através de suas práticas e discussões coletivas o conceito de ambiente, distinguindo este conceito daquele de natureza. (Figura $2 b$.)

Os textos relativos ao conceito de natureza e ambiente são reveladores da capacidade de compreensão e construção do conhecimento de forma lúdica, envolvendo, neste caso, a dimensão artística, ou seja, artes plásticas aproximativas elaboradas por meio da construção de maquete e pintura com tintas naturais. São também reveladores de uma construção que permite diferenciar os conceitos previamente concebidos. Ficou evidenciado nos exemplos das Fig. $2 \mathrm{a}$ e b que os alunos são capazes de entender e diferenciar entre a natureza e o ambiente mesmo que, em tal faixa etária, crianças do $5^{\mathrm{o}}$ ano do ensino fundamental essa seja uma construção ainda de noções. 


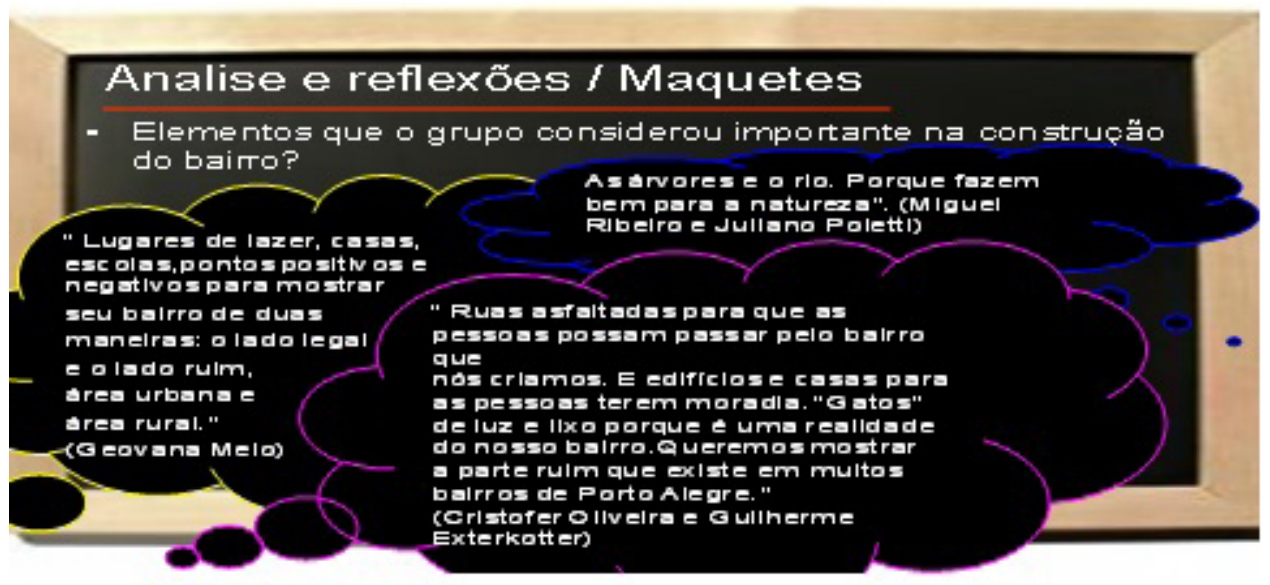

Analise e reflexöes / Maquetes

- O que é AMEIENTE para o grupo? Importância de discussäo?

"Antigamente, nós achávamos que o ambiente era a natureza, mas depois das oficinas descobrimos que o ambiente é aonde nós

vivemos. E é importante

discutir este tema para poder

saber como arrumar e cuidar dos ambientes

que estudamos." (Crist of

Oliveirae Guilherme

Exterkotter)

Ambierte é a relação dos elementos da natureza com o meio urbano. quase tudo ou tudo que se tem no meio urbano depende da natureza. Em fim, é a natureza tranforormada. (Geov aпа Melo)

"Para nós ambiente é onde vivemose o que devemos preservar. A importância de discutir os problemas do nosso bairro é para tertarmosfazer com que as pessoas pensem antes de tocar lixo. poluir e desmatar." (Andressa Almeida e Garoline Palma)

Figura 2a. Apresentação dos resultados relativos à construção dos alunos sobre o ambiente do bairro. Figura 2b. Apresentação dos resultados sobre a construção de noções/conceitos de natureza e ambiente. Projeto Educação ambiental - Vivências no urbano. Elaborado por Kornalewski da Silva, 2008. Relatório FAPERGS, inédito.

\section{CONTAÇÃO DE HISTÓRIAS: LITERATURA E GEOGRAFIA}

Esta é uma atividade que vem se desenvolvendo em vários espaços, seja no ensino formal com alunos do Colégio de Aplicação da UFRGS, seja em eventos, encontros ou outros espaços informais. A atividade teve seu início com a autoria de texto literário composto por temas geográficos. Desde a produção desse texto, a autora, Rossato (2009), promove oficinas denominadas "contação de histórias". Estas são contadas de forma ilustrada, ou seja, utilizando bonecos dos personagens e objetos que ilustram a obra, construídos com finalidade didática, Figura 4. O tema do livro versa sobre uma viagem ao espaço cósmico. Tema considerado complexo para as crianças dessa faixa etária, porém de grande interesse e curiosidade.

Na sequência de fotos observa-se a professora numa atividade informal, numa "contação de história" para professores de Geografia durante um evento nacional da área em 2010 e em sala de aula. Observa-se nas fotos que os personagens e os objetos que ilustram o livro foram transformados em objetos manipuláveis. Assim, as crianças ou mesmo os professores podem interagir fazendo per- 
guntas, apreendendo através do toque nos objetos e observando suas formas e funções. Os conceitos trabalhados na história, além dos relativos ao espaço, aos planetas, ao movimento da Terra, aos dias e às noites são associados, também, ao clima, aos tipos de nuvens e à origem das chuvas.

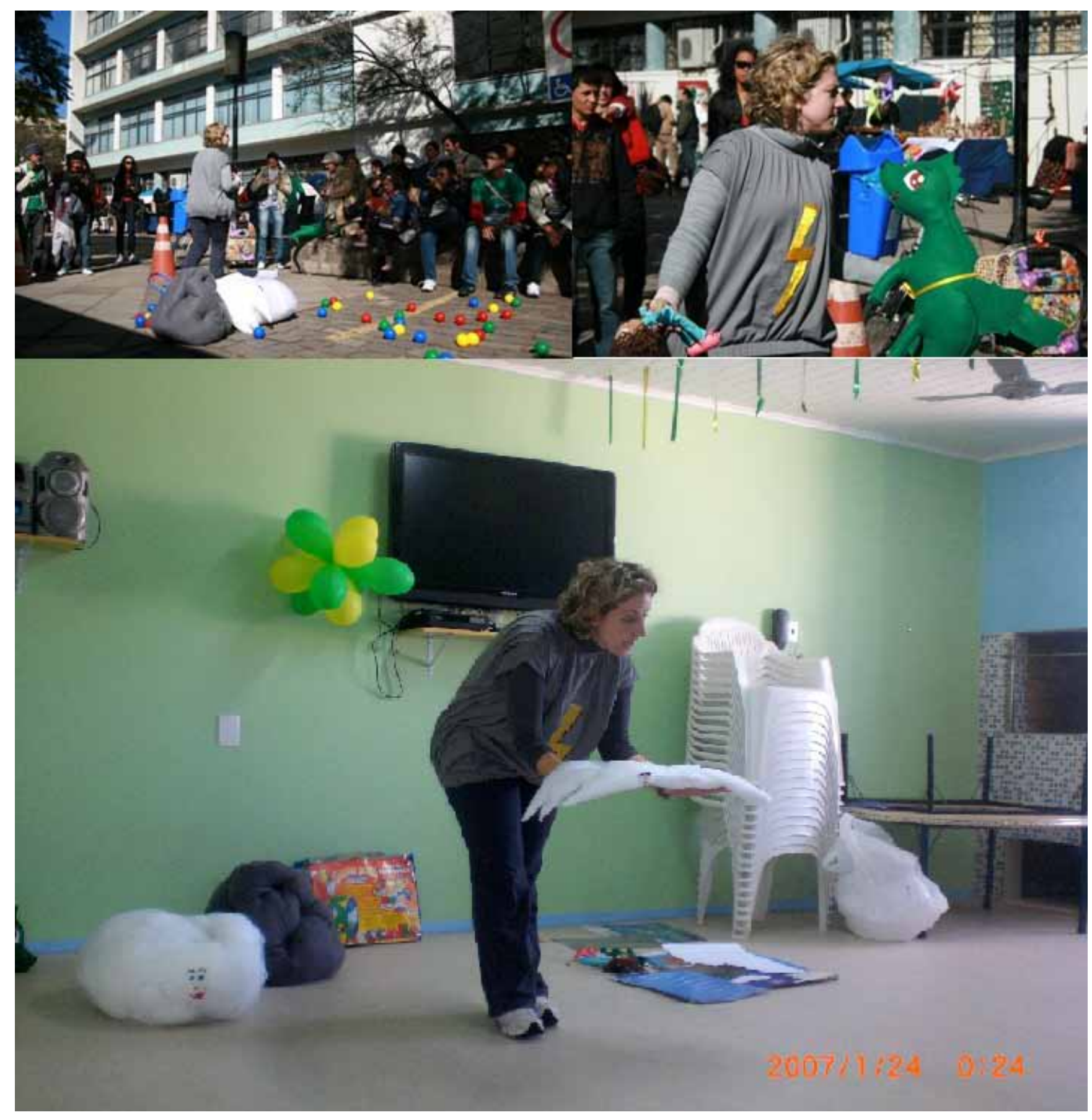

Figura 4. Contação de histórias para professores - XVI Encontro Nacional de Geógrafos e em sala de aula. Porto Alegre, 2010.

Este outro exemplo é revelador de, pelo menos, três dimensões artísticas na construção da aprendizagem: a produção do texto literário, a produção dos personagens e a contação de história. Configurando-se a contação de história atualmente, denominada de "performance", numa possibilidade de novas expressões provenientes dessa prática, além do aprendizado de conceitos geográficos bási- 
cos. Ou, ainda, estímulo às práticas interdisciplinares através da associação da atividade de contar história com conteúdo geográfico com outras disciplinas desse nível escolar.

Durante o Salão Jovem de Iniciação Científica, promovido pela UFRGS 2011, alunos de outros anos do ensino fundamental, inspirados nessa contação de história, elaboraram, na continuidade de suas atividades, com a professora de Ciências do CAP/UFRGS, pesquisa e desenvolvimento de objetos dos mais variados tipos. Foram produzidos maquetes e equipamentos, montados com base em suas iniciativas, para demonstrarem, por exemplo, o movimento de rotação da Terra, os dias e as noites, entre outros fenômenos.

Esta proposta, portanto, apresenta-se como uma possibilidade já evidenciada de articulação entre diferentes campos disciplinares, no caso, Geografia, Artes e Ciências.

\section{PAISAGENS E REPRESENTAÇÕES: AREAIS DO RS}

Este projeto foi dirigido aos alunos do CEFET de São Vicente do Sul/RS e tinha como objetivo construir uma atividade que permitisse aos alunos uma reflexão estética e científica sobre os areais, feições arenosas entre o campo, presentes na Campanha do Rio Grande do Sul/Bioma Pampa. As atividades foram iniciadas com uma palestra: "Paisagens dos areais gaúchos".

Segundo o autor Pires da Silva (2008):

a palestra estava constituída por uma série de imagens que enfatizavam não só a dinâmica e a gênese do processo de arenização no sudoeste gaúcho, mas, sobretudo, provocaria no público participante uma viagem sobre as paisagens registradas nas artes plásticas, em especial nos pintores europeus encabeçados por Monet. Adicionei muitas imagens que captavam os vestígios da fauna local e as diferentes composições da flora própria dessas manchas de areias" (2008, p. 119).

Na continuidade de seu relato, Pires da Silva (2008) informa que:

nas colocações iniciais, após o tempo dado para que cada um dos presentes, incluindo professoras que acompanharam o grupo na atividade de campo e até mesmo o estudante monitor que estava auxiliando na projeção, solicitei que descrevessem uma paisagem idearia de ser admirada e de ter como companhia; falei-lhes da importância do processo de pensar e repensar nosso dia a dia, formulando questões para pesquisa, em que a prática questionadora e investigativa interpenetrasse nossas atividades cotidianas, que o processo de pesquisar não fosse uma prática reservada a alguns "escolhidos", mas norma de conduta de todo profissional (Pires da Silva, 2008, p 122).

A palestra pôde ser concebida como um momento de aprendizagem e sensibilização para a etapa seguinte o que, na escolha do autor da proposta, correspondeu a um trabalho de campo em um dos areais, previamente escolhido. Durante a palestra, este realizou desenhos com os alunos sobre paisagens registradas em suas memórias, e, na continuidade:

Optou pela atividade de vivência direta com a paisagem local, numa perspectiva "[...] de integrar a paisagem pessoal na paisagem ecológica, incorporar os mapas de memória com a maneira como habitamos uma bio-região (Thomashow, 1995, p. 285, In: Pires da Silva, 2008, p. 120).

O resultado desta atividade foi expresso pelos jovens por meio de desenhos, poesias e fotos. Abaixo, são apresentados, em forma de exemplo, alguns desses resultados. Fig. 5, 6 e 7. 


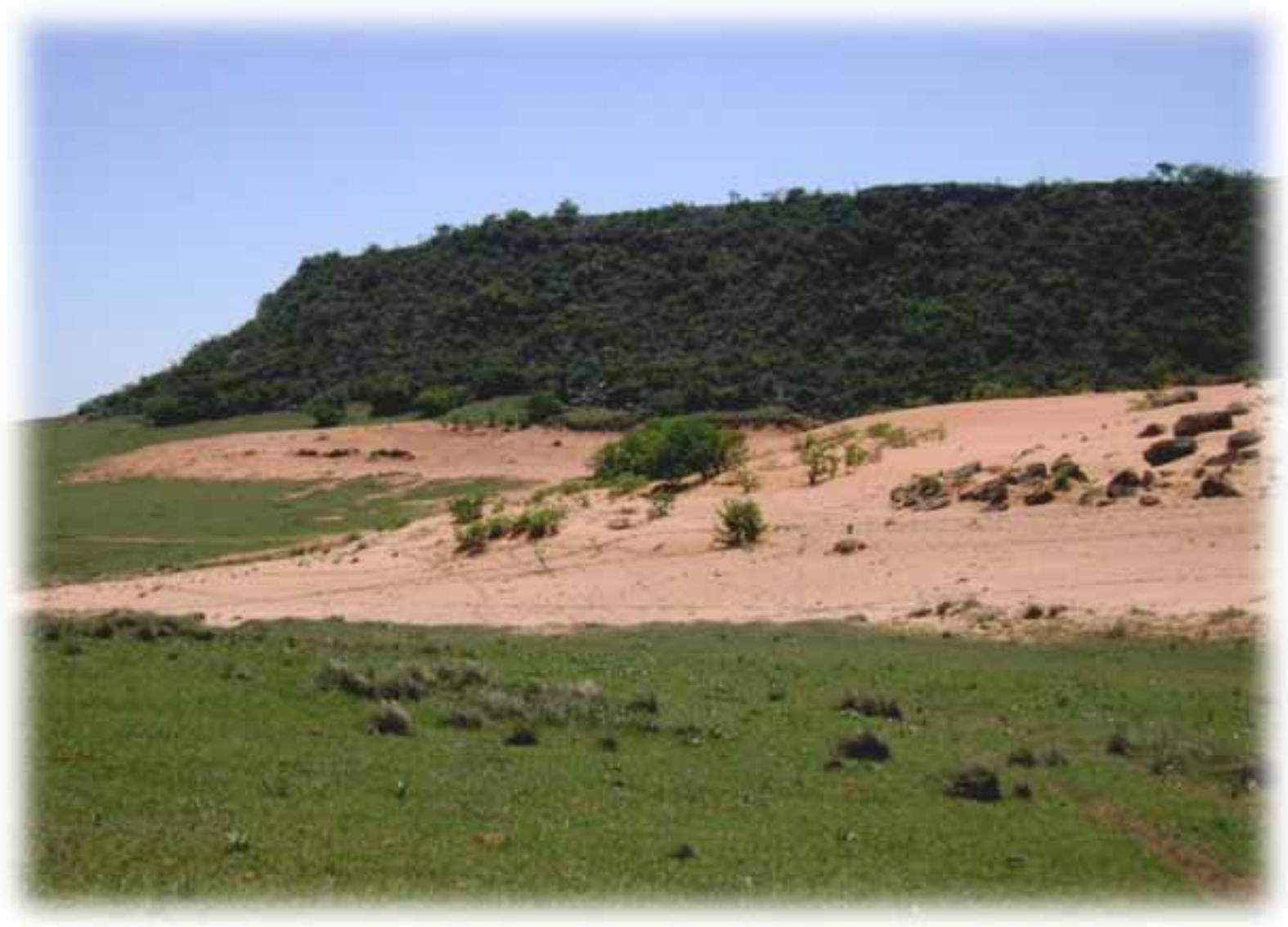

Figura 5. Fotografia produzida pelo estudante Luca Pivetta nos areais da propriedade do Sr. Joaquim Paz, São Francisco de Assis. Extraído de Pires da Silva, 2008,p. 134.

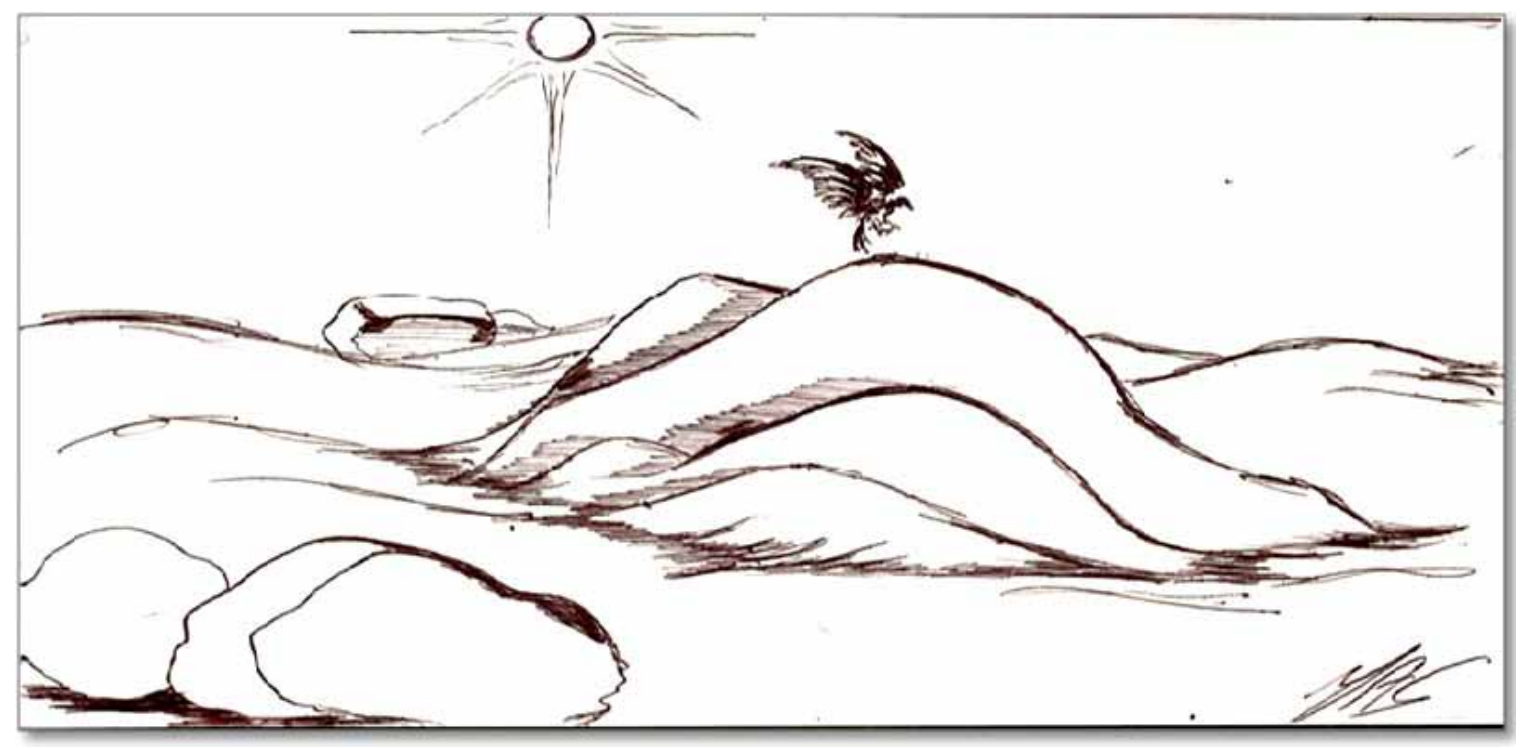

Figura 6. Imagem representada pelo estudante do CEFET Jonatas Almeida da Silva, Concebe um ponto já no interior do areal junto ao Cerro da Esquina na propriedade do Sr. Paz, em São Francisco de Assis. Extraído de Pires da Silva, 2008, p. 137.

$\mathrm{Na}$ continuidade, é apresentada outra forma de manifestação artística revelada na poesia da Figura 7. 


\section{Luta desigual}

Em uma terra,

De ecossistema frágil,

A degradação é mais ágil,

Do que as atitudes de recuperação.

E assim a luta é desigual,

A vida quase não resiste,

Quem ali vive persiste,

A agressão atrevida

Do bicho homem.

Que por sua ganância,

E na ânsia,

De acumular,

Degrada seu próprio lar.

Usando a tecnologia,

Faz do progresso,

Uma utopia,
Crivada de demagogia.

Até quando a mãe natureza,

Vai resistir?

O que será que vai existir,

Para as gerações futuras?

Cenários de filmes,

Aos poucos agonizam,

Choram sagram,

Rios de lagrimas,

Pelos crimes,

Contra o ecossistema.

O fim,

Por favor,

Não,

Isto não pode ser assim.

\section{Helenésio Cabral, Anderson Teixeira, Cleber Colling e \\ Márcio Noronha.}

Figura 7. Poema expressando as reflexões sobre a imagem captada em trabalho de campo nos areais Município de São Francisco de Assis/RS. Extraído de Pires da Silva, 2008, p. 138.

Esta atividade expressa em seu conjunto um procedimento que parte da observação, para, na continuidade, explorar vários procedimentos. O conceito central de tal proposta para ensinar Geografia foi o de paisagem. O entendimento dos processos observados e interpretados em campo se transformou em representações reveladoras de conhecimento adquirido e explicitou saberes e aptidões pouco revelados.

\section{UMA LEITURA SOBRE OS PROJETOS}

Para proceder essa leitura retomo Ratzel, para este:

A primeira exigência feita à ciência e à arte é a fiel observação da natureza. Para aquele que quer descrever [interpretar] a natureza, os fenômenos naturais e os processos físicos têm que estar presentes, também para aquele que quer investigá-los. Ambos precisam dispor de um grande conhecimento dos assuntos da natureza; portanto, a obra de arte e a lei da natureza nascem, ambas, apenas da comparação entre as suntuosas impressões sensíveis retidas por uma forte lembrança (Ratzel, 2008, p. 162). 
O texto de Ratzel que tomamos como referência neste artigo indica como elo entre Ciência e Arte, nos estudos da natureza, a observação. Este procedimento é clássico na Geografia e associa-se ao trabalho de campo, também, um procedimento da maior importância entre aqueles que estudam a natureza. Dos três projetos descritos dois deles trazem em sua proposta a atividade de campo com vistas à observação do que se deseja ensinar/aprender.

Contemporaneamente, além do campo, uma gama muito grande de possibilidades permite a compreensão dos fenômenos da natureza. A história infantil dramatizada com base em objetos que reproduzem elementos da natureza é reveladora de possibilidades múltiplas à medida que as crianças, especialmente aquelas em fase inicial de aprendizagem, podem manipular os objetos, transformando as representações em situações reais em seus imaginários.

Revela-se nessa experiência essa dupla articulação: de um lado a observação da natureza transformada em representação, de outro as representações transformadas em conhecimento da natureza. Para além do conhecimento científico, essas vivências expressam a possibilidade do desenvolvimento de aptidões artísticas e sensibilidade além de procedimentos atitudinais. Curiosidade, criatividade, criticidade, investigação, proposições e reflexões estão sempre presentes em projetos dessa dimensão. Estas são atitudes que projetos de ensino como estes podem estimular.

Mas as novas propostas, que emergem no ensino de Geografia, não são reveladoras, somente, de procedimentos e atitudes. Elas estão acompanhadas de um desejo de produção de conhecimento, de ampliação de conhecimento. Isso se constata na ênfase dada em cada um dos projetos e conceitos e/ou conteúdos específicos da Geografia. Os projetos aqui trabalhados buscaram refletir e construir conceitos como os de natureza, ambiente e paisagem, bem como promoveram a construção de conhecimento sobre espaço/planetas/satélites, movimentos da Terra, estações do ano, tipos de nuvens, precipitações, entre outros.

Tais práticas são fundamentais na atualidade conforme o processo educativo precisa ser reinventado. Reinventar a educação, reinventar novas linguagens para reinventar nossa compreensão de natureza são possibilidades educacionais para a Geografia. No entanto, para reconceituar a natureza é preciso refletir sobre suas representações, como explicita Gonçalves:

A natureza se define, em nossa sociedade, por aquilo que se opõe à cultura. A cultura é tomada como algo superior e que conseguiu controlar e dominar (domesticar) a natureza. Cultura se coloca como oposto ao que é natural, natureza (Gonçalves, 1998).

Ou, segundo a proposição de Maturana, percebe-se que:

Para recuperar essa harmonia fundamental que não destrói, que não explora, que não abusa, que não pretende dominar o mundo natural, mas que deseja conhecê-lo na aceitação e respeito para que o bem-estar humano se dê no bem-estar da natureza em que se vive. Para isso é preciso aprender a olhar e escutar sem medo de deixar de ser, sem medo de deixar o outro ser em harmonia, sem submissão. Quero um mundo em que respeitamos o mundo natural que nos sustenta, um mundo no qual se devolva o que se toma emprestado da natureza para viver. Ao sermos seres vivos, somos seres autônomos, no viver não o somos (Maturana, 2001, p. 124).

Enfim, para finalizar, busco novamente parte do texto da epígrafe. Nele, pode ser observado o que expõe Gonçalves (1998) ao se referir à natureza, em especial, no continente que constitui nossa morada. 
Em toda a América, e no mundo, continuamos pagando as consequências desse divórcio obrigatório.

A natureza não é muda.

Eduardo Galeano, 2010.

A escola, e nela a ciência geográfica, apresentam essa possibilidade de reler o mundo, reler a natureza, sensibilizar por meio da arte e inovar a partir do que Ratzel já discutia, ao se referir ao ensino da natureza, nos níveis fundamentais e médios.

Nossas crianças e nossos jovens aguardam pelo novo e o instigante. $\mathrm{O}$ mundo atual não é o mundo de Ratzel. A Geografia, o ensino da Geografia, ainda, em grande parte, se debate com as formas do passado, criticando-as, contrariando-as, entretanto, ideias clássicas, como estas de Ratzel, referindo-se à interpretação da Natureza, por vezes, sem conhecê-las, são retomadas na contemporaneidade como um caminho possível na educação e, em particular, na Geografia. A articulação Ciência e Arte e uma entre tantas outras sugestões de transdisciplinaridade. O caminho da imaginação criativa é uma possibilidade que a educação nos tempos atuais deveria ter em consideração. São muitas as possibilidades que permitem a ultrapassagem das velhas formas de ensinar, arraigadas em procedimentos que, muitas vezes, mesmo com o uso de tecnologias modernas, se reproduzem de forma pouco inspiradora, seja para ler a natureza, seja para apreender o mundo que nos cerca.

\section{BIBLIOGRAFIA}

Galeano, E. A natureza não é muda. Portal Rizomas. <www.rizomas.net/component/taxonomy/ Eduardo\%20Galeano.html>. Acesso em: nov. de 2010.

Gonçalves, Carlos W. P. (1998). Os (des) caminhos do meio ambiente. São Paulo: Contexto.

Maturana, H. (2001). Cognição, ciência e vida cotidiana. Belo Horizonte: Ed. UFMG.

Ratzel, F. (2010). Sobre a interpretação da natureza [Über Naturschilderung]. GEOgraphia. 12 (23), p. $157-176$.

Rossato, M. S. (2009). Dandara, o dragão e a lua. Porto Alegre: Cassol.

Kornalewski, P. (2008). Educação ambiental: Vivencias no urbano. Trabalho apresentado no ENG. São Paulo.

Pires da Silva, L. A. (2008). Narrativas das percepções e conectividades de caminhantes nas paisagens dos areais pampeanos: perspectivas ambientais para geração de ambiências. Dissertação (Mestrado em Geografia), Universidade Federal do Rio Grande do Sul. Porto Alegre.

Santos, M. (1997). A natureza do espaço: técnica e tempo: razão e emoção. São Paulo: Hucitec.

Suertegaray, D. M. A.(2003). Avaliação Nacional dos Livros Didáticos de $5^{\mathrm{a}}$ a $8^{\mathrm{a}}$ Séries - PNLD 2005, área de Geografia. Brasília, Trabalho técnico.

. (2007). Avaliação PNLD 2009. Geografia. Brasília. Trabalho Técnico. 
(2008). Avaliação PNLD 2010. Geografia. Brasília. Trabalho Técnico.

(2009). Avaliação PNLD 2011. Geografia. Brasília. Trabalho Técnico.

Artículo recibido 20 - 09 - 11. Aprobado 25 - 11 - 11 . 